\title{
Inland water Hydrographic Survey for Mapping and Scientific Research
}

\author{
Enrico Zanone ${ }^{\mathrm{a}}$, Erik Biscotti ${ }^{\mathrm{b}}$, Aldo Monaca ${ }^{\mathrm{c}}$, Marco Pucci ${ }^{\mathrm{d}}$ * \\ ${ }^{a}$ Italian Hydrographic Institute, enrico.zanone@marina.difesa.it \\ ${ }^{b}$ Italian Hydrographic Institute, erikd.biscotti@marina.difesa.it \\ ${ }^{c}$ Italian Hydrographic Institute, aldo.monaca@marina.difesa.it \\ ${ }^{d}$ Italian Hydrographic Institute, marco_pucci@marina.difesa.it \\ * Corresponding author
}

Keywords: Cartography, Lake, Hydrographic Survey, Scientific Research

\begin{abstract}
:
The Italian Hydrographic Institute (IIM) is the National Agency for nautical cartography under command of the Italian Navy, and is located in Genova since its foundation in 1872. Its tasks include the production of nautical charts and documents aimed at the safety of navigation, and extend to the processing of scientific, technological and environmental data connected with the sea. Therefore, the IIM activity mainly develops within three fields: production, applied research and education. In the domain of production, the IIM provides users with the official nautical documents and disseminates nautical information, both at a national and international level, in order to contribute to the safety of navigation and to the safeguard of human life at sea. As regards oceanography the IIM sees to the collection and processing of the physical and chemical parameters of the water masses and of particular hydrologic features. Our activities include the experimentation of prototypes of nautical, oceanographic and meteorological instruments to further the advancement of nautical sciences, in cooperation with Universities and scientific institutions. The IIM represents Italy within the International Hydrographic Organization (IHO), which is appointed to coordinate the activity of the National Hydrographic services, to see to the standardization of nautical documents, and to promote international cooperation in the development of the hydrooceanographic techniques and surveys. The activity of the IIM within the IHO is mostly aimed at the production of international charts of the Mediterranean, and at the technical assistance to the hydrographic services of emerging Mediterranean countries.
\end{abstract}

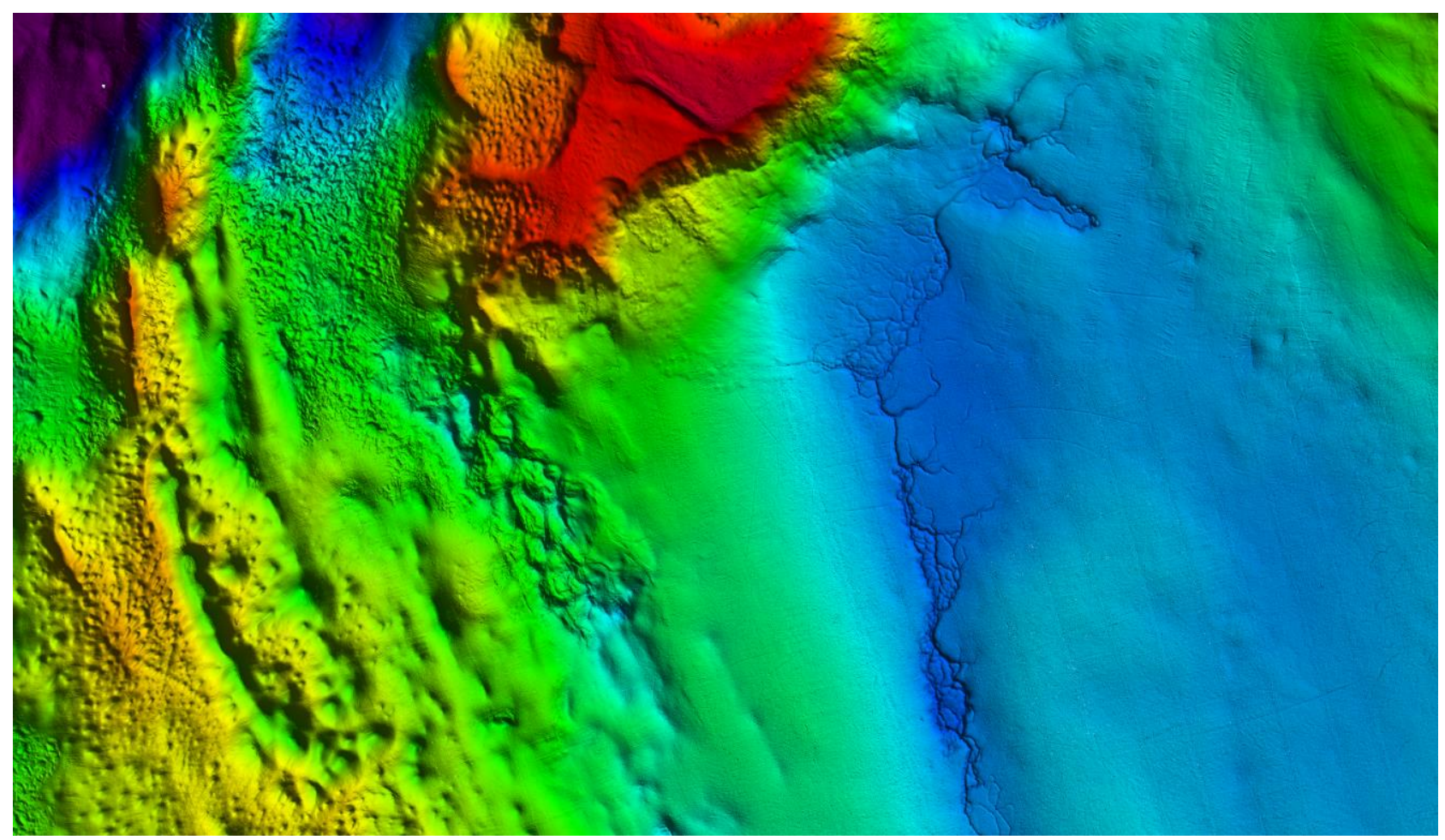

Figure 1.Fault between the locality of Sirmione and Punta San Virgilio. 
In 2018 the Italian Navy Hydrographic Institute of Genova -IIM- and the "Università Cattolica del Sacro Cuore" of Brescia started a collaboration for the study and research of Lake Garda and the Subalpine Lakes seabed, a project called "Accurate Climate Change Unified Risk Assessment for Territory and Environment in sub-alpine lakes (ACCURATE) ", carrying out the bathymetric survey of the entire Lake of Garda for the development of the model-numerical analysis for the morphology of the seabed in the scientific research field. The aim is to create an accurate simulation of water motion of the above-mentioned basin in relation to extreme climatic events or danger to the population.

The study showed how a three-dimensional morphology of the bottom, obtained thanks to a high resolution bathymetry, it is possible to simulate the deep and surface currents, creating a model on the motion of water, its temperature, waves, the spread of bacteria, pollutants and of the seaweed. The results showed a complex geological structure with craters, canyons, furrows and faults never seen before. Above all, it highlighted a fault between the locality of Sirmione and Punta San Virgilio (Figure 1) whose existence was known only for local geological dynamics, but which had never been identified with this resolution.

The Italian Hydrographic Institute carried out the execution of the aforementioned hydrographic survey with an hydrographic launch, MBf 1213, equipped with a multibeam sonar in dual-head configuration, able to guarantee high resolution, accuracy and precision in data acquisition.

In the three-year period 2018/19/20 the specialist team of the IIM worked for a total of 96 days of execution of the survey, including an area of $371 \mathrm{~km}^{2}$ and covering 1500 nautical miles of survey line.

Furthermore, the survey of the seabed will contribute to the safety of navigation and to the protection of the lake environment by updating the databases and related cartography of the IIM portfolio (Bathymetric Map n. 862 "Lake Garda - Benaco", scale 1: 50,000).

In summary, the collaboration between the IIM and the "Università Cattolica del Sacro Cuore" represents an excellent example of synergy in scientific research, which strengthens the dual capacity of the IIM even in non-marine environments. The result of a three-dimensional bathymetric model, developed by the hydrographers of the IIM, represents a fundamental element for the protection of the lake environment and consequently for all the activities that gravitate around the Garda basin. 